\title{
Self-assembling benzothiazole-based gelators: a mechanistic un- derstanding of in vitro bioactivation and gelation
}

\author{
Francesca Citossi, ${ }^{a}$ Thomas Smith, ${ }^{a}$ Jong Bong Lee, ${ }^{a}$ Joel Segal, ${ }^{a}$ Pavel Gershkovich, ${ }^{a}$ Michael J.

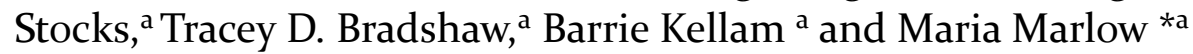

\author{
a School of Pharmacy, University of Nottingham, University Park, Nottingham, NG7 2RD, UK. \\ *E-mail: maria.marlow@nottingham.ac.uk
}

KEYWORDS: benzothiazole derivatives, low molecular weight gelators, CYPıA1 induction, in vitro antitumour activity

\begin{abstract}
Low molecular weight gelators (LMWGs) of chemotherapeutic drugs represent a valid alternative to the existing polymerbased formulations used for targeted delivery of anticancer drugs. Herein we report the design and development of novel self-assembling gelators of the antitumour benzothiazole ${ }_{5} \mathrm{~F} 203$ (1). Two different types of derivatives of 1 were synthesized, formed by an amide (2) and a carbamate (3a-3d) linker, respectively, which showed potent in vitro antitumour activity against MCF-7 mammary and IGROV-1 ovarian carcinoma cells. In contrast, MRC-5 fibroblasts were inherently resistant to the above derivatives $\left(\mathrm{GI}_{50}>10 \mu \mathrm{M}\right)$, thus revealing stark selectivity against the malignant cell lines over the non-transformed fibroblasts. Western blots assays demonstrated induction of CYP1A1 by 1 and its derivatives only in sensitive malignant cells (MCF-7), corroborating conservation of CYPıA1-mediated mechanism of action. The ability to form stable gels under relatively high strains was supported by rheological tests; in addition, their inner morphology was characterized as possessing a crossed-linked nanostructure, with formation of thick aggregates with variable widths between $1100 \mathrm{~nm}$ and $400 \mathrm{~nm}$ and lengths from $8 \mu \mathrm{m}$ to $32 \mu \mathrm{m}$. Finally, in vitro dissolution studies proved the ability of hydrogel 2 to release $48 \%$ of 2 within 80 hours, therefore demonstrating its ability to act as a platform for localized delivery.
\end{abstract}

\section{INTRODUCTION}

Low molecular weight gelators (LMWGs) have recently become an attractive group of soft biomaterials with exceptional tunable properties that make them suitable for drug delivery applications. ${ }^{1-3}$ They have been reported to be viable alternatives to the extensively explored polymer-based drug delivery systems, due to their biocompatibility, biodegradability and ability to control drug release. One of the most successful applications of LMWGs involves the design of self-assembling derivatives as stimuli-responsive biomaterials. ${ }^{4}$ This approach consists of covalently conjugating functional moieties, such as peptides, amino acids or fatty acids, to active drugs, in order to create amphiphilic derivatives which self-assemble in different solvents (mainly water) to form a gel depot, from which the active agent is released after hydrolysis or enzymatic degradation. 5 To date, examples of antibacterial, anti-inflammatory and chemotherapeutic LMWGs developed with this strategy have been reported. 3, 6,7 In particular, LMWGs of chemotherapeutic drugs represent a valid alternative to the existing polymer-based formulations used for targeted delivery of anticancer drugs, because of their higher drug loading, lack of excipients, and consequent increased in situ drug concentrations. ${ }^{3}$ To date, most of the examples in the literature of chemotherapeutic LMWGs are those reported by $\mathrm{Xu}$ and Yang, based on the anticancer drug paclitaxel. They exploited short peptides and folic acid as functional moieties to create several examples of $\mathrm{Taxol}^{\circledR}$ hydrogels for targeted cancer therapy. ${ }^{8-10}$ A recent comprehensive review by $\mathrm{Xu}$ and his collegues summarized the methods used to generate supramolecular hydrogels and their applications as molecular biomaterials." Our group recently reported another example of a chemotherapeuticbased LMWG. We synthesized amino acid deriavtives of the experimental anticancer agent 2-(4-amino-3methylphenyl)-5-fluorobenzothiazole $\left({ }_{5} \mathrm{~F} 203,1\right)$, which formed metastable gels in mixtures of organic solvents (DMSO) and water. Amino acid derivatives of $\mathbf{1}$ also displayed in vitro activity against ovarian and breast cancer cell lines. ${ }^{12} \mathbf{1}$ was initially selected for these studies as it had been previously identified as the lead compound of a family of benzothiazole derivatives with exquisitely potent and highly selective antitumour activity in certain tumour models including breast and ovarian cancer cell lines. ${ }^{13}, 14$ Its mechanism of action is distinct from chemotherapeutic agents in the clinical arena. After binding to the cytosolic arylhydrocarbon receptor (AhR), the complex of $\mathbf{1}$ and $\mathrm{AhR}$ translocate to the nucleus; dimerise with AhR nuclear transportor and bind to the xenobiotic response element in the promotor region of genes in the AhR battery including cypıa1 ${ }^{15,16}$ Induction of cypıa transcription and protein expression results in $\mathrm{CYP}_{1} \mathrm{~A}_{1}$-catalysed bioactivation of $\mathbf{1}$ to electrophilic reactive species, ${ }^{13,17}$ which generate DNA adducts leading to lethal DNA strand breaks and cell death. ${ }^{18}$ The lysylamide derivative of $\mathbf{1}$, Phortress, developed to overcome $\mathbf{1}$ high lipophilicity and poor aqueous solubility, ${ }^{19}$ was progressed to clinical trials. ${ }^{20}$ Including our recent gel 
studies, very few examples of self-assembling benzothiazole derivatives have been reported in the literature, which refer to formation of organogels from binary mixtures. ${ }^{21,22}$ Herein, we have further developed novel self-assembling gelators based on 1. In particular, we have identified two different types of derivatives of $\mathbf{1}$ formed by an amide (2) and a carbamate (3) linker, respectively (Fig. 1). We also show how structural differences led to different in vitro and
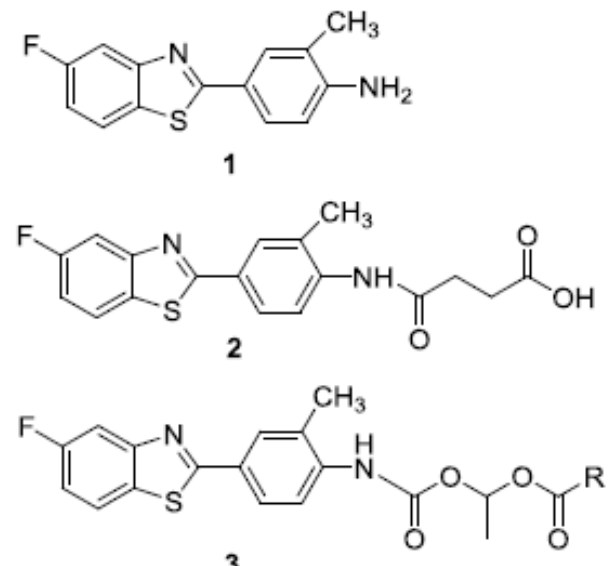

Figure 1: Molecular structures of $\mathbf{1}$, the succinic amide derivative (2) and the carbamate-based derivatives $\left(\mathrm{R}=\mathrm{CH}_{3}, \mathrm{CH}_{2} \mathrm{CH}_{3}, \mathrm{CH}\left(\mathrm{CH}_{3}\right)_{2}\right.$, $\left.\mathrm{C}\left(\mathrm{CH}_{3}\right)_{3}\right)$ (3a-3d).

gelation properties. Finally, we selected a lead derivative of 1 for further studies, demonstrating the potential applications of this gelator in drug delivery.

\section{EXPERIMENTAL SECTION}

Materials. Chemicals, solvents and buffers were purchased from commercial suppliers and were used without further purification. Cell culture medium, supplements and foetal bovine serum were purchased from Sigma Aldrich. Human plasma was purchased from TCS Biosciences.

General methods. Reactions were monitored by thin layer chromatography (TLC) on commercially available precoated aluminium-backed plates (Merck Kieselgel 6o F254).Visualisation was carried out by examination under UV light $(254 \mathrm{~nm})$ or by staining with potassium permanganate $\left(\mathrm{KMnO}_{4}\right)$ solution. Organic solvents were evaporated under reduced pressure at temperatures between 35 ${ }^{\circ} \mathrm{C}$ and $45{ }^{\circ} \mathrm{C}$ (water bath). Purification by silica gel flash column chromatography was performed using silica gel Sigma Aldrich (technical grade, 40-63 $\mu \mathrm{m}$ particle size).

Analytical Methodology. ${ }^{1} \mathrm{H}$ NMR spectra were recorded on a Bruker 400 Ultrashield at $400 \mathrm{MHz}$ at $25{ }^{\circ} \mathrm{C}$. ${ }^{13} \mathrm{C}$ NMR spectra were recorded on a Bruker 400 Ultrashield at 100 $\mathrm{MHz}$ at $25^{\circ} \mathrm{C}$. Chemical shifts $(\delta)$ are reported in parts per million (ppm). DMSO- $\mathrm{d}_{6}$ was used as solvent for NMR analyses $\left(\left(\mathrm{CHD}_{2}\right)_{2} \mathrm{SO}\right.$ at $\delta \mathrm{H} 2.50 \mathrm{ppm},\left(\mathrm{CD}_{3}\right)_{2} \mathrm{SO}$ at $\delta \mathrm{C} 39.52$ ppm). The significant multiplicities are described by singlet (s), doublet (d), triplet (t), doublet of a doublet (dd), triplet of a doublet (td) and multiplet (m). Coupling constants (J) are recorded in Hz. Spectra were analyzed with Bruker TopSpin 3.o. High-resolution mass spectra (HRMS)-time of flight electrospray (TOF ES \pm ) were recorded using Waters 2795 spectrometer. Melting points were measured on Gallenkamp Melting Point Apparatus. Reverse phase high performance liquid chromatography (RP-HPLC) was performed using a Waters 2767 sample manager, Waters 2525 binary gradient module and visualized at $254 \mathrm{~nm}$ with a Waters 2487 dual wavelength absorbance detector. Spectra were analyzed using MassLynx. Preparative RP-HPLC was performed using a Phenomenex Luna $10 \mu \mathrm{m} \mathrm{C8} \mathrm{(2)} 100 \AA$ column (150 mm x $30 \mathrm{~mm})$ at a flow rate of $20 \mathrm{~mL} / \mathrm{min}$ using a preparative RP-HPLC method of o-16 min gradient of $40 \%$ to $80 \%$ solvent $B$ in solvent $A, 16-18$ min held at $80 \%$ solvent $B$ in solvent $A, 18$ 20 min $80 \%$ to $40 \%$ solvent B in solvent A, 20-22 min held at $40 \%$ solvent B in solvent A. Analytical RP-HPLC was performed using a Phenomenex Luna $5 \mu \mathrm{m}$ C8 (2) $100 \AA$ column $(150 \mathrm{~mm} \times 4.60 \mathrm{~mm})$ at a flow rate of $1 \mathrm{~mL} / \mathrm{min}$. The retention time $\left(t_{R}\right)$ of products is reported using an analytical RP-HPLC method of o-24 min gradient of $5 \%$ to $95 \%$ solvent B in solvent A, 24-26 min held at 95\% solvent B in solvent A, 26-27 min 95\% to 5\% solvent B in solvent A, 2730 min held at $5 \%$ solvent $B$ in solvent $A$ (solvent $A=0.05$ $\%$ TFA in $\mathrm{H}_{2} \mathrm{O}$, solvent $\mathrm{B}=0.05 \%$ TFA in 9:1 $\mathrm{v}: \mathrm{v}$ $\mathrm{CH}_{3} \mathrm{CN}: \mathrm{H}_{2} \mathrm{O}$ ).

HPLC analyses of benzothiazole derivative stability tests: To $100 \mu \mathrm{L}$ sample, $10 \mu \mathrm{L}$ internal standard solution $(100 \mu \mathrm{M}$ diclofenac in acetonitrile-water $(1: 1, v / v)$ ) was added. Protein precipitation was accomplished by addition of $300 \mu \mathrm{L}$ acetonitrile. A pH modifier of $300 \mu \mathrm{L}$ o.1 M HCl and $2 \mathrm{~mL}$ extraction solvent metyl-tert-butyl ether were added for liquid-liquid extraction. A vortex-mix of 10 min was applied and the samples were centrifuged at $1160 \mathrm{~g}$ for $10 \mathrm{~min}$ at 10 ${ }^{\circ} \mathrm{C}$. The organic layer was transferred and evaporated to dryness under $\mathrm{N}_{2}$ gas at $40{ }^{\circ} \mathrm{C}$. The samples were reconstituted with $100 \mu \mathrm{L}$ acetonitrile-water (1:1, v/v) and vortexmixed for 1 min prior to HPLC analysis. The HPLC-UV system consisted of a Waters 6oo Pump, Waters $717 \mathrm{Au}$ tosampler and Waters 2996 Photodiode Array Detector. Chromatographic separation was accomplished by Gemini C18 2.0 x $150 \mathrm{~mm}, 3 \mu \mathrm{m}$ particle size column equipped with a SecurityGuard $2 \times 4 \mathrm{~mm}, 3 \mu \mathrm{m}$ particle size (Phenomenex, Macclesfield, UK). A mixture of acetonitrile-water was used for mobile phase in ratios of 60:40 $(\mathrm{v} / \mathrm{v})$ at a flow rate of $0.35 \mathrm{~mL} / \mathrm{min}$. Chromatograms were observed at 347, 325 and $278 \mathrm{~nm}$ for $\mathbf{1}$, the derivatives of $\mathbf{1}$ and diclofenac, respectively.

Synthesis of compound 2. 2-(4-Amino-3-methylphenyl)5 -fluorobenzothiazole ( $5 \mathrm{~F} 203,1 ; 1.94 \mathrm{mmol}, 0.50 \mathrm{~g})$ and succinic anhydride (46.56 mmol, $4.65 \mathrm{~g}$ ) were suspended in dry pyridine $(30 \mathrm{~mL})$ and the reaction mixture was stirred at $60{ }^{\circ} \mathrm{C}$ to effect full dissolution and the solution was then maintained at this temperature for a further $15 \mathrm{~h}$. 
The cooled solution was evaporated under reduced pressure to afford a semi-solid material which was then triturated with water to aid removal of residual pyridine. The solid was then collected via vacuum filtration and purified using preparative RP-HPLC (o.29 g, 42\% yield). ${ }^{1} \mathrm{H}$ NMR (400 MHz, DMSO-d $\left.)_{6}\right): \delta 12.15(\mathrm{~s}, 1 \mathrm{H}, \mathrm{COOH}), 9.45(\mathrm{~s}, 1 \mathrm{H}$, $\mathrm{NH}), 8.17(\mathrm{dd}, 1 \mathrm{H}, \mathrm{J}=5.4,8.8 \mathrm{~Hz}, \mathrm{H}-7), 7.94(\mathrm{~d}, \mathrm{~J}=1.7 \mathrm{~Hz}$, $\left.{ }_{1} \mathrm{H}, \mathrm{H}-4\right), 7.89-7.85$ (m, 2H, H-2', H-6'), 7.76 (d, J= 8.7 Hz, 1H, H-5'), 7.36 (td, J= 2.5, $8.9 \mathrm{~Hz}, 1 \mathrm{H}, \mathrm{H}-6), 2.66(\mathrm{t}, \mathrm{J}=6.5$ $\mathrm{Hz}, 1 \mathrm{H}, \mathrm{CH} 2-\mathrm{COOH}), 2.55\left(\mathrm{t}, \mathrm{J}=6.3 \mathrm{~Hz}, 1 \mathrm{H}, \mathrm{CH}_{2}\right), 2.34(\mathrm{~s}$, $3 \mathrm{H}, \mathrm{CH}_{3}$ ). ${ }^{13} \mathrm{C}$ NMR (10o MHz, DMSO-d 6 ): 173.79, 170.49, 169.79, 162.58, 16o.19, 154.54, 139.8o, 130.16, 128.98, 125.15, 123.63, 113.77, 113.52, 108.70, 108.47, 30.78, 29.04, 17.82. Mp: 222-224 ${ }^{\circ} \mathrm{C}$. MS: $\mathrm{m} / \mathrm{z}$ (HRMS) calculated for $\mathrm{C}_{18} \mathrm{H}_{16} \mathrm{FN}_{2} \mathrm{O}_{3} \mathrm{~S}^{+}$ 359.086o $[\mathrm{M}+\mathrm{H}]$, MS found: $359.0938[\mathrm{MH}]^{+}$. Analytical $\mathrm{RP}-\mathrm{HPLC} \mathrm{tR}=17.16 \mathrm{~min}$.

General synthetic procedure of carbamate derivatives (3a-3d). 1 (1 eq) was suspended in dry $\mathrm{CH}_{2} \mathrm{Cl}_{2}$ at o ${ }^{\circ} \mathrm{C}$ and dry pyridine ( $2 \mathrm{eq}$ ) and 1-chloroethyl chloroformate (1.2 eq) were added dropwise. The resulting reaction mixture was stirred at $\mathrm{o}{ }^{\circ} \mathrm{C}$ for $15 \mathrm{~min}$ and then warmed to r.t. and stirred for a further $3 \mathrm{~h}$. Water was poured into the reaction mixture and the crude product was extracted 3 times with $\mathrm{CH}_{2} \mathrm{Cl}_{2}$ and dried over $\mathrm{Na}_{2} \mathrm{SO}_{4}$. Crude 1-chloroethyl-5F 203 carbamate was used for the following reaction without further purification. 1-chloroethyl-5F 203 carbamate (1 eq) was suspended into the corresponding acid (35$40 \mathrm{eq})$ and heated at $70{ }^{\circ} \mathrm{C}$. $\mathrm{Ag}_{2} \mathrm{O}$ (1.2 eq), was added and the reaction mixture heated up to $95^{\circ} \mathrm{C}$ and stirred for $3 \mathrm{~h}$. $\mathrm{Ag}_{2} \mathrm{O}$ was removed via filtration and the filtrate was collected and concentrated under reduced pressure to afford a yellow oil which was further purified by silica gel flash chromatography (gradient elution 10-30\% EtOAc in petroleum ether $40-60{ }^{\circ} \mathrm{C}$ ). Compounds $3 \mathbf{a}-\mathbf{3 d}$ were obtained from trituration in hexane to remove the residual acids. For specific experimental procedures, NMR and HPLC analyses and yield of all carbamate analogues (3a-3d), please see supplementary information (SI.1-SI.16).

Cell culture. Human-derived $\mathrm{MCF}-7$ (oestrogen receptor positive), HTC-116 colorectal and IGROV-1 ovarian carcinoma cells, obtained from the American Type Culture Collection (ATCC), were cultured at $37{ }^{\circ} \mathrm{C}$ in a humidified atmosphere comprising $5 \% \mathrm{CO}_{2}$ in a Sanyo LEEC incubator. Human-derived cancer cells were grown in RPMI 1640 (Sigma Aldrich) cell culture medium supplemented with $10 \% \mathrm{v} / \mathrm{v}$ foetal bovine serum (FBS, Sigma Aldrich) and routinely subcultured twice weekly to maintain continuous logarithmic growth. Normal lung fibroblasts (MRC- -5 human-derived) were grown in Eagle's minimum essential medium (MEM, Sigma Aldrich) supplemented with 10\% $\mathrm{v} / \mathrm{v}$ FBS, 100 units penicillin per $\mathrm{ml}$ and $0.01 \mathrm{mg}$ per $\mathrm{ml}$ streptomycin (Sigma Aldrich), 5\% v/v L-glutamine (200 nM, Sigma Aldrich), 5\% v/v non-essential amino acids (Sigma Aldrich), 5\% v/v hepes solution (1 M, Sigma Aldrich) and $5 \% \mathrm{v} / \mathrm{v}$ sodium bicarbonate solution $(7.5 \%$, Sigma Aldrich). Experiments were set up when cultures reached approximately $70-80 \%$ confluence. Experimental agents were prepared as $10 \mathrm{mM}$ stock solutions dissolved in DMSO and stored at $4{ }^{\circ} \mathrm{C}$, protected from light for a maximum period of 4 weeks.

Growth inhibitory assays (MTT assays). 1 and derivatives 2 and 3a-3d were prepared as $10 \mathrm{mM}$ top stocks in DMSO. Cells were seeded at a density of $3 \times 10^{3}$ per well into 96-well microtiter plates and allowed to adhere for 24 $\mathrm{h}$ before test agent was introduced (final concentrations 1 $\mathrm{nM}-10 \mu \mathrm{M}, \mathrm{n}=4)$. Serial dilutions were prepared in RPMI 1640 medium immediately prior to addition in each assay. At the time of agent addition and following $72 \mathrm{~h}$ exposure, 3-(4,5-dimethylthiazol-2-yl)-2,5-diphenyltetrazolium bromide (MTT) was added to each well (final concentration $400 \mu \mathrm{g} / \mathrm{mL}$ ). Incubation at $37^{\circ} \mathrm{C}$ for $2.5 \mathrm{~h}$ allowed reduction of MTT by viable cells (mitochondrial dehydrogenases) to insoluble formazan crystals. Well supernatants were removed, and formazan solubilized by addition of DMSO $(150 \mu \mathrm{L})$. Absorbance was read at $550 \mathrm{~nm}$ using a Perkin Elmer plate reader. Non-linear regression analysis was used to calculate compound concentrations required to inhibit cell growth by 50\% $\left(\mathrm{GI}_{50}\right)$.

Western Blot. Whole cell lysates were prepared for examination of $\mathrm{CYP}_{1} \mathrm{~A}_{1}$ protein expression from untreated $\mathrm{MCF}$ 7 and HCT-116 cultures and following exposure of cells to compounds $(1 \mu \mathrm{M}$ 1, $1 \mu \mathrm{M}$ 3a, $10 \mu \mathrm{M}$ 2; $72 \mathrm{~h})$. Following protein determination $(n=3)$ and addition of sample buffer, samples were heated to $95^{\circ} \mathrm{C}$ for $5 \mathrm{~min}$ and solubilized proteins $(50 \mu \mathrm{g})$ were separated by sodium dodecyl sulphate (SDS) polyacrylamide gel electrophoresis (PAGE). Proteins were electroblotted to polyvinylidene difluoride membranes and probed for CYP1A1 protein with polyclonal antiserum specific for human CYP1A1 (Sigma Aldrich). Secondary $\mathrm{Ab}$ was conjugated to horseradish peroxidase, and CYP1A1 was detected by enhanced chemiluminescence. Monoclonal anti-GAPDH Ab was used to verify equal protein loading and transfer. Molecular weight markers and a positive control of recombinant $\mathrm{CYP}_{1} \mathrm{~A}_{1}(5 \mu \mathrm{g}$; Sigma Aldrich), included in blots, confirmed detection of $58 \mathrm{kDa}$ CYP1A1 protein.

Stability test in human plasma and cell growth medium. Human plasma and cell growth medium (RPMI, $10 \% \mathrm{FBS}$ ) were used to determine enzymatic stability of the benzothiazole derivatives 2 and 3 . The medium was preheated to $37^{\circ} \mathrm{C}$ prior to the assay for $5 \mathrm{~min}$. The experiment was initiated by spiking stock solutions of the benzothiazole derivatives 2 and $3 a$ to give a concentration of $10 \mu \mathrm{M}$. The reaction mixtures were incubated at $37{ }^{\circ} \mathrm{C}$ and shaken at $200 \mathrm{rpm}$ on a temperature-controlled orbital shaker (Thermo Scientific MaxQ40oo, Waltham, MA, USA). Samples of $100 \mu \mathrm{L}$ were withdrawn at pre-determined time points and the reaction was terminated by addition of acetonitrile. All experiments were conducted in triplicate.

Benzothiazole derivative stability test in MCF-7, HCT116 cells and their growth medium. Derivative 2 was prepared as a $10 \mathrm{mM}$ stock solution in DMSO. MCF-7 and 
HCT-116 cells were cultured at $37{ }^{\circ} \mathrm{C}$ in RPMI 1640 medium supplemented with $10 \% \mathrm{FBS}$, in $75 \mathrm{~cm}^{3}$ flasks. Flasks were prepared in triplicate for each time point: $24 \mathrm{~h}, 48 \mathrm{~h}, 72 \mathrm{~h}$. Post-seeding $(120 \mathrm{~h})$ the medium was aspirated and replaced with $15 \mathrm{~mL}$ RPMI 1640 medium supplemented with $2 \%$ FBS. The $10 \mathrm{mM}$ stock solution was diluted to $10 \mu \mathrm{M}$, the cells were treated with $15 \mu \mathrm{L}$ producing a final concentration of $1 \mu \mathrm{M}$. At the respective time points, $1 \mathrm{~mL}$ of culture medium was collected for analysis. The remainder was aspirated and the cells were washed with $2 \times 4 \mathrm{~mL}$ PBS prior to trypsinization. The cells were collected and centrifuged in $50 \%$ PBS in medium at $1200 \mathrm{rpm}$ for $5 \mathrm{~min}$. Supernatant $(1 \mathrm{~mL})$ was collected for analysis and the remainder was aspirated leaving a cell pellet. Cell pellets were weighed and PBS added 1:1 (w/v). These samples were vortex-mixed and $100 \mu \mathrm{L}$ was withdrawn for sample preparation for HPLC analysis (see "Analytical Methodology" section for HPLC analyses).

Preparation of Gels. Method A. Samples (5 mg) were weighed into $1.5 \mathrm{~mL}$ sample vials using an OHAUS semi micro-analytical balance. Ultra-purified water $(0.5 \mathrm{~mL})$ was added and the suspension was sonicated for $1 \mathrm{~min}$. A $0.5 \mathrm{M}$ solution of $\mathrm{NaOH}(30 \mu \mathrm{L})$ was then added and the mixture was sonicated until a clear solution was obtained. Glucono- $\delta$-lactone (GdL, o.7 molar equivalents) was added to the solution which was vortexed for $1 \mathrm{~min}$ (HatiRotamixer). Samples were then allowed to stand for $12 \mathrm{~h}$. Vial inversion tests were subsequently carried out as preliminary screens for gelation. All samples prepared had a final concentration of $1 \% \mathrm{w} / \mathrm{v}$.

Preparation of Gels. Method B. The compounds were weighed into $1.5 \mathrm{~mL}$ sample vials. DMSO was added to create a stock solution at $10 \% \mathrm{w} / \mathrm{v}$. The solution was then sonicated in a Sonicor Ultra-sonic bath for $1 \mathrm{~min}$ and successively heated at $60^{\circ} \mathrm{C}$ to help full dissolution of the compound. An aliquot $(25 \mu \mathrm{L})$ of the stock solution was transferred to another $1.5 \mathrm{~mL}$ vial; the remaining DMSO and pre-heated $\left(60^{\circ} \mathrm{C}\right)$ ultra-purified water were added. Samples were then allowed to cool to room temperature. Vial inversion tests were subsequently carried out as preliminary screens for gelation. All samples prepared had a final concentration of $0.5 \% \mathrm{w} / \mathrm{v}$.

Rheology. Rheological studies were carried out using an Anton Paar MCR302 Modular Compact Rheometer. A fourbladed vane geometry was used, with a diameter of $8.5 \mathrm{~mm}$ and length $8.5 \mathrm{~mm}$ in a cup with a diameter of $14.5 \mathrm{~mm}$. Preparation of hydrogels of 2 was carried out in a $7 \mathrm{~mL}$ Sterilin plastic sample vial with gelation method $\mathrm{A}$, to make a $2 \mathrm{~mL}$ gel $(1 \% \mathrm{w} / \mathrm{v})$. After gelation was considered complete $(12 \mathrm{~h})$, the vial containing the gel was mounted in the lower plate of the rheometer (cup) and then the vane (attached to the upper part) was lowered into place. This arrangement gave a sample depth of approximately $16 \mathrm{~mm}$ in the $14.5 \mathrm{~mm}$ diameter cup which allowed positioning of the vane in the centre of the sample. Measurements of the storage modulus $\left(\mathrm{G}^{\prime}\right)$ and loss modulus $\left(\mathrm{G}^{\prime \prime}\right)$ as function of strain $\gamma$, were carried out at a frequency of $10 \mathrm{rad} / \mathrm{s}$. Oscillatory frequency sweeps were performed within the linear viscoelastic region (LVR) of the gel sample, where $G^{\prime}$ and $G^{\prime \prime}$ moduli are independent of the strain amplitude, under a strain of $1 \%$. Preparation of gels of 3 was carried out in a $7 \mathrm{~mL}$ Sterilin plastic sample vial with gelation method B to make gels of $2 \mathrm{~mL}$ volume $(0.5 \% \mathrm{w} / \mathrm{v})$. Rheological studies were performed according to the procedure detailed above. For these gels, measurements of $G^{\prime}$ and $G^{\prime \prime}$ as function of strain $\gamma$, were carried out at a frequency of $10 \mathrm{rad} / \mathrm{s}$. Oscillatory frequency sweeps were performed under a strain of $0.5 \%$. All measurements were carried out at $37^{\circ} \mathrm{C}$.

Transmission Electron Microscopy (TEM). TEM analyses were performed using a JEOL JEM-2100 at an accelerated voltage of $200 \mathrm{kV}$. A $10 \mu \mathrm{L}$ micropipette was used to load a small amount of gel on to a graphene oxide lacey carbon hexagonal copper grid (300 mesh, Agar). Excess sample was blotted with Whatman 50 filter paper. The grid was subjected to high vacuum prior to imaging. Image J software was used to analyse TEM images.

Dissolution studies. Hydrogels of $2(1 \% \mathrm{w} / \mathrm{v} ; 0.4 \mathrm{~mL})$ were prepared according to method $\mathrm{A}$. The liquid solution was pipetted into transwell polyethylene terephthalate (PET) membrane inserts (pore size 1.0 $\mu \mathrm{m}$, Greiner Bio One) and allowed to gel for approximately $12 \mathrm{~h}$. The transwells were then inserted into 24 well plates containing $1.2 \mathrm{~mL}$ of PBS ( $\mathrm{pH} 7.4$ ) and incubated in a Thermo Scientific MaxQ 4000 Shaker at $37^{\circ} \mathrm{C}$ at $15 \mathrm{rpm}$. At each time point a sample $(150 \mu \mathrm{L})$ was removed from each solution and replaced with the same amount of fresh PBS buffer. Analyses were performed on a HP1050 RP-HPLC and visualized at $254 \mathrm{~nm}$ with a HP1050 variable wavelength absorbance detector. Spectra were analyzed using Agilent. Analytical RP-HPLC was performed using a Phenomenex Luna $5 \mu \mathrm{m} \mathrm{C8} \mathrm{(2)} 100 \AA$ column (150 mm x 4.6o mm) at a flow rate of $1 \mathrm{~mL} / \mathrm{min}$. Samples were analyzed using an isocratic method: $70 \%$ solvent $B$ in solvent $A$ (solvent $A=0.05$ $\%$ TFA in $\mathrm{H}_{2} \mathrm{O}$, solvent $\mathrm{B}=0.05 \%$ TFA in 9:1 $\mathrm{v}: \mathrm{v}$ $\mathrm{CH}_{3} \mathrm{CN}: \mathrm{H}_{2} \mathrm{O}$ ). Quantification of known concentrations of 2 was determined by UV-HPLC measurements and used to produce two standard curves, from which unknown concentrations of both compounds were determined.

All data are expressed as mean +/- SD unless stated otherwise

\section{RESULTS}

The previously reported amino acid derivatives of 1 were developed with the aim of creating LMWGs which displayed in vitro activity against cancer cell lines. However, these previously reported derivatives formed metastable gels in mixtures of organic solvents (DMSO) and water. ${ }^{12}$ In order to further develop more biocompatible and potent gelators of derivatives of $\mathbf{1}$, two different approaches have been considered. The first strategy involved the design and synthesis of esterase-sensitive carbamate derivatives of $\mathbf{1}$ (3a-3d), in particular acyloxyalkoxycarbonyl derivatives, as 
previously reported by the pioneering work of Alexander et al. ${ }^{25,}{ }^{26}$ In addition to this, a second strategy was also considered, with the aim of comparing the rate of conversion of these derivatives into the parent drug and avoiding the rapid esterase-mediated hydrolysis. The design choice was based on the analysis of the most commonly used linkers in the synthesis of stable prodrugs of amines, such as amides, esters, carbamates, phosphates or oximes. ${ }^{23}$ Several examples of $N$-acylated prodrugs have been reported either as successful drugs or in late stage clinical development. ${ }^{24}$ Therefore, an approach linking 1 to a succinic acid moiety via an amide bond was chosen to increase the derivative stability and reduce susceptibility to esterase activity. The succinic acid moiety itself was designed to include an alkyl chain linked to a terminal free carboxylate. These two functional groups were used as the hydrophobic forces in combination with water solubility, given by a "pH switch", to promote the self-assembly process. Synthetic procedures of the carbamate derivatives of $\mathbf{1}$ are described in the Supporting Information (SI.5-SI.16).

The growth inhibitory properties of compound $\mathbf{2}$ and the series of carbamate analogues (3a-3d) were then corroborated by MTT assay following $72 \mathrm{~h}$ exposure of cells to the test agents. Table 1 shows the differential activity against mammary MCF-7 and ovarian IGROV-1 carcinoma cells. Activity against MRC-5 normal lung fibroblast cells was also evaluated.

\begin{tabular}{cccc}
\hline Compounds & \multicolumn{3}{c}{ GI5o mean \pm SEM (nM) } \\
\cline { 2 - 4 } & MCF-7 & IGROV-1 & MRC-5 \\
\hline $\mathbf{1}$ & $38.82 \pm 4.25$ & $138.24 \pm 51.76$ & $>10000$ \\
\hline $\mathbf{2}$ & $4754.80 \pm 1119.36$ & $5325.85 \pm 1312.75$ & $>10000$ \\
\hline $3 \mathbf{a}$ & $11.63 \pm 3.07$ & $43.81 \pm 4.75$ & $>10000$ \\
\hline $3 \mathbf{b}$ & $22.57 \pm 7.98$ & $157.35 \pm 80.77$ & $>10000$ \\
\hline 3c & $39.88 \pm 5.32$ & $4261.08 \pm 1438.28$ & $>10000$ \\
\hline 3d & $81.22 \pm 38.18$ & $83.10 \pm 11.16$ & $>10000$
\end{tabular}

Table 1. Growth inhibitory properties of 1 , compound $\mathbf{2}$ and carbamate derivatives 3a-3d against MCF-7, IGROV-1 and MRC-5 cell lines.

When MCF-7 cancer cells were exposed to derivatives of $\mathbf{1}$, all derivatives retained activity against this cell line. In particular, the acyloxyalkoxycarbonyl analogues $3 \mathbf{a}-\mathbf{3} \mathbf{d}$ showed potent growth inhibitory activity at nanomolar concentrations, with $\mathrm{GI}_{50}$ values similar to those of the parent amine $\mathbf{1}\left(\mathrm{GI}_{50}<100 \mathrm{nM}\right)$. The succinic acid derivative $\mathbf{2}$ displayed $\mathrm{GI}_{5 \mathrm{o}}$ values in the micromolar range $(4.75 \mu \mathrm{M})$. MTT assays of compound 2 against IGROV-1 revealed micromolar activity with a $\mathrm{GI}_{50}$ value of $5.33 \mu \mathrm{M}$. Carbamate derivatives 3a, $3 \mathbf{b}$ and $3 \mathbf{d}$ displayed $\mathrm{GI}_{50}$ values $<200 \mathrm{nM}$, similar to those of the parent amine $\mathbf{1}(138.24 \mathrm{nM})$. Compound $3 \mathrm{c}$ exhibited higher $\mathrm{GI}_{50}$ values (reduced potency) in the micromolar range, i.e. $4.26 \mu \mathrm{M}$. In both $\mathrm{MCF}-7$ and IGROV-1 cell lines, dose-dependent inhibition of cancer cell growth was observed. In order to demonstrate the selectivity of these derivatives against cancer cell lines, MTT assays against the MRC-5 normal human embryonic lung fibroblast cell line were conducted. MRC-5 fibroblasts were inherently resistant to $\mathbf{1} ; 1^{18}$ similarly, none of the derivatives 2 and 3a-3d showed any growth inhibitory activity at the maximum concentration tested $(10 \mu \mathrm{M})$, thus revealing stark selectivity against the malignant cell lines over the non-transformed fibroblasts. Selectivity is also evident between cancer phenotypes, for example, HCT-116 colorectal carcinoma cells are insensitive to $1\left(\mathrm{GI}_{50}>50 \mu \mathrm{M}\right) .{ }^{13}$ To test the hypothesis that modification does not lead to changes in the mechanism of action of $\mathbf{1}$, western blot assays were performed to examine $\mathrm{CYP}_{1} \mathrm{~A}_{1}$ protein expression in lysates following treatment of cells (MCF-7 and HCT-116) with 1 and its derivatives. Compounds $\mathbf{2}$ and 3 a were included in this study. In particular, amongst the acyloxyalkoxycarbonyl analogues, za was selected because of its remarkable in vitro activity displayed against MCF-7 and IGROV-1 cancer cell lines compared to the other derivatives. In accordance with benzothiazole selectivity, neither constitutive nor induced $\mathrm{CYP}_{1} \mathrm{~A}_{1}$ expression could be detected in lysates of HCT-116 cells exposed to $\mathbf{1}, \mathbf{2}$ and $3 \mathbf{3}$. In contrast, in sensitive MCF-7 cells exposed to 1 or za $(1 \mu \mathrm{M} ; 72 \mathrm{~h})$, powerful induction of $\mathrm{CYP}_{1} \mathrm{~A} 1$ protein was detected. Correlating with its weaker growth inhibitory activity, succinic acid derivative 2 (10 $\mu \mathrm{M} ; 72 \mathrm{~h})$ gave more faintly induced CYP1A1 protein expression (Fig. 2).

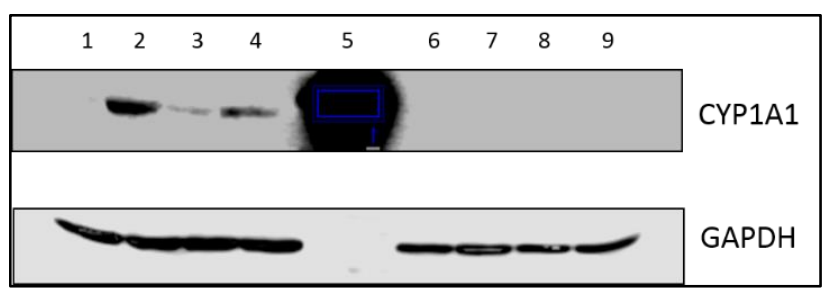

Figure 2. Selective induction of CYP1A1 protein in MCF-7 (lanes 1-4), but not HCT 116 (lanes (6-9) lysates following $72 \mathrm{~h}$ exposure of cells to vehicle alone (lanes 1 and 6), $\mathbf{1}$ (lanes 2 and 7), $\mathbf{2}$ (lanes 3 and 8) or $3 a$ (lanes 4 and 9). Lane 5 shows detection of recombinant CYPıA1 $(5 \mu \mathrm{g})$ positive control. Cell lysates containing $50 \mu$ g protein were loaded into each well. GAPDH protein detection ensured equal electrotransfer of proteins onto membranes.

The next step towards development of LMWG-based benzothiazole derivatives was assessment of their in vitro stability properties in cell growth medium and human plasma. Compounds 2 and $\mathbf{3 a}$ were chosen as candidates for these tests. The succinic acid derivative $\mathbf{2}$ displayed stability in both cell growth medium, supplemented with $10 \%$ FBS, and human plasma, ruling out extracellular cleavage of compound 2. On the contrary, when the carbamate derivative za was incubated in cell growth medium and human plasma, complete conversion into 1 occurred, thus suggesting its susceptibility to cleavage by extracellular enzymes (SI.29). The half-lives of the carbamate derivative 3 a were $4.18 \pm 0.27 \mathrm{~h}$ and $1.61 \pm 0.11 \mathrm{~h}$ in cell growth medium 
and human plasma, respectively. No additional peaks other than the peak for 1 were observed in the HPLC-UV chromatograms suggesting direct conversion to 1 (Fig. 3). Further evaluation of the stability of succinic acid derivative 2 was carried out in MCF-7 sensitive and HCT-116 insensitive cells and their culture media. In insensitive HCT-116 cells of $\mathbf{1}$, as we have confirmed, $C \mathrm{PP}_{1} \mathrm{~A}_{1}$ is not induced, therefore $\mathbf{1}$ is not bioactivated, and lipophilic $\mathbf{1}$ is able

(A) Cell growth medium

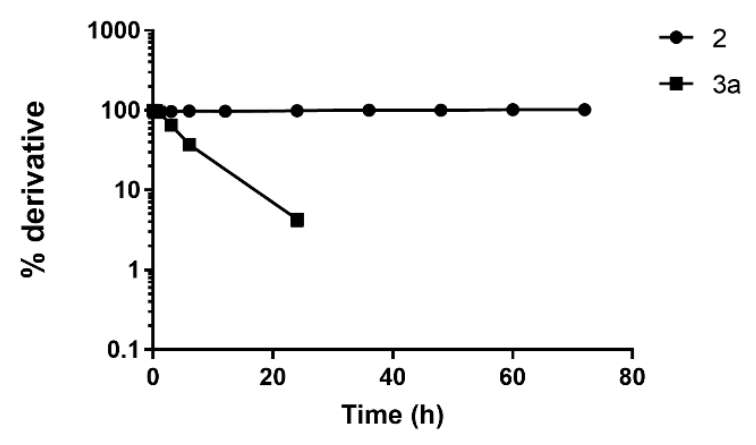

(B) Human plasma

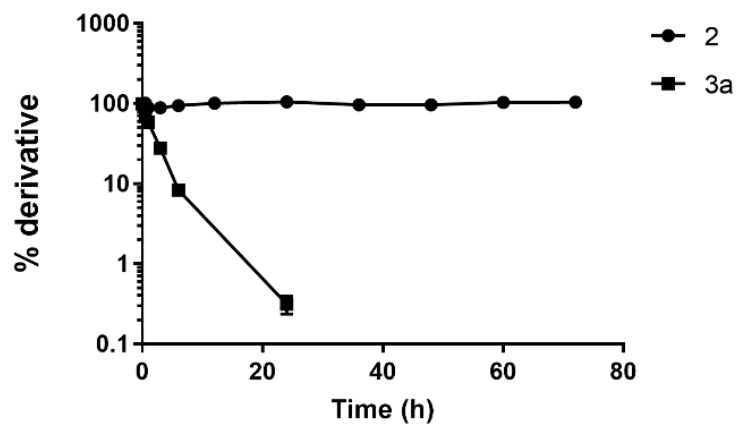

Figure 3: Stability of 2 and $3 a(1 \mu \mathrm{M})$ in (A) cell growth medium and (B) human plasma, $\mathrm{n}=3$.

to diffuse passively across the HCT-116 cell membrane. The hypothesis under investigation was that released $\mathbf{1}$ may be detected by HPLC in the insensitive cells. In contrast, sensitive MCF-7 cells rapidly sequester 1 as it binds to cytosolic arylhydrocarbon receptor (AhR) triggering AhR pathway activation and $\mathrm{CYP}_{1} \mathrm{~A}_{1}$ induction.

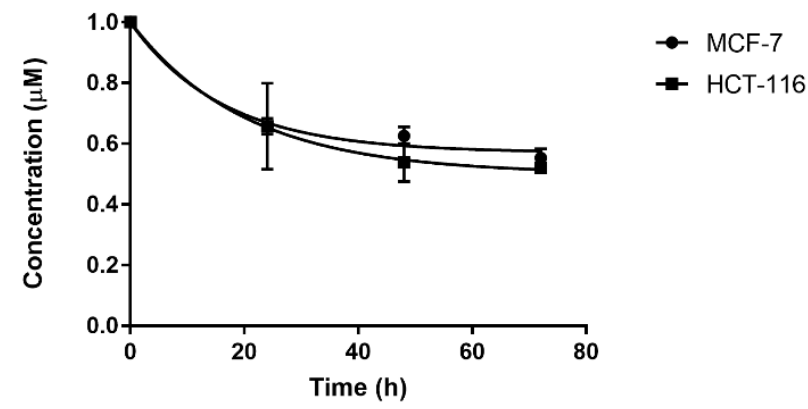

Figure 4: The depletion of $2(1 \mu \mathrm{M})$ from cell growth medium, supplemented with $2 \%$ FBS, of MCF-7 and HCT-116 cells, $n=3$.
Cells were treated with $1 \mu \mathrm{M}$ benzothiazole derivative and analysed at 24 h, $48 \mathrm{~h}$ and $72 \mathrm{~h}$. As shown in Fig. 4, depletion of succinic acid derivative 2 from the cell growth medium was comparable in both MCF-7 and HCT-116 cells. However, > 6-fold enhanced intracellular levels of 2 were detected in MCF-7 lysates compared to HCT-116 lysates. 1 was detected in neither sensitive nor insensitive cells (Fig. 5).

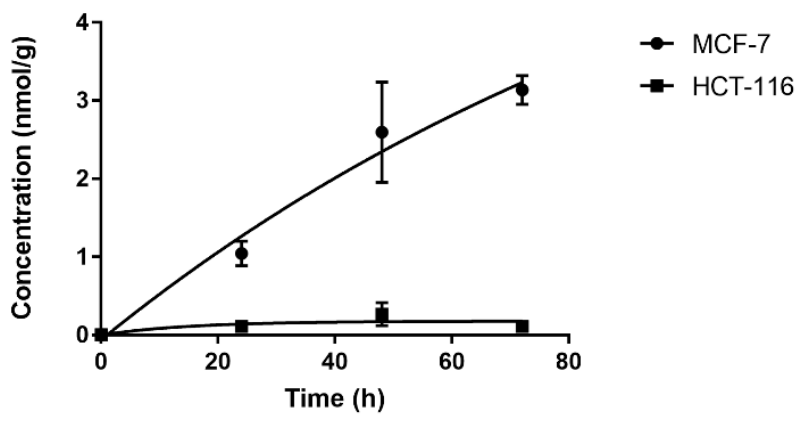

Figure 5: Concentration of 2 in MCF-7 and HCT-116 cells over time, $n$ $=3$

In MCF-7 cells, any released $\mathbf{1}$ would trigger AhR pathway activation and be translocated to nuclei. Low levels of $\mathbf{1}$ released from $\mathbf{2}$ and subsequent bioactivation are consistent with faint $\mathrm{CYP}_{1} \mathrm{~A}_{1}$ induction by succinic acid derivative $\mathbf{2}$ and $>100$-fold reduced activity compared with free amine $\mathbf{1}$ and rapidly hydrolysable carbamate derivative $3 \mathbf{a}\left(\mathrm{GI}_{50}\right.$ values $4.75 \mu \mathrm{M}$ compared with $<40 \mathrm{nM}$ respectively) in $\mathrm{MCF}-7$ cells. Further investigation revealed emergence of a concentration-dependent unknown peak only in cell lysates of insensitive HCT-116 cells; suggesting breakdown or metabolism of derivative $\mathbf{2}$ (SI.28).

The next step in the development of LMWG derivatives of $\mathbf{1}$ was the formulation and characterization of gels of $\mathbf{2}$ and 3a-3d. Hydrogels of $\mathbf{2}$ were prepared using a $\mathrm{pH}$ switch method, as previously reported in the literature (method A). ${ }^{27}$ Gels of $3 \mathbf{a}-\mathbf{3 c}$ were prepared in binary mixtures of DMSO and water at different ratios, with solvent volume fractions $\phi D M S O$ up to 0.4 .

Oscillatory amplitude sweeps (SI.24) of hydrogel 2 (1\% $\mathrm{w} / \mathrm{v}$ ), were performed over a strain from 0.5 to $100 \%$, at a constant angular frequency of $10 \mathrm{rad} / \mathrm{s}$ and at $37{ }^{\circ} \mathrm{C}$, to mimic the physiological conditions at which the gel would be used for drug delivery purposes. Results revealed the presence of a LVR, with only a slight decrease of the storage modulus at high strains. For both amplitude and frequency sweeps $G^{\prime}$ values were higher than $G^{\prime \prime}$ values of at least one order of magnitude, as a representative characteristic of LMWGs. ${ }^{1}$ Frequency sweeps were performed over a frequency from 0.1 to $100 \mathrm{rad} / \mathrm{s}$, using a constant strain of $1 \%$. A frequency dependence of $G^{\prime}$ and $G^{\prime \prime}$ was displayed throughout the values tested, with $G^{\prime}$ and $G^{\prime \prime}$ curves displaying a gradually inclining slope with increasing frequencies, attributable to a low degree cross-linked network (Fig. 6A). Amongst the acyloxyalkoxycarbonyl derivatives, 3a-3c formed visually stable gels in the preliminary vial inversion tests, whilst compound $3 \mathbf{d}$ did not gelate any of the solvent 
fractions tested. Analyses of analogue za were carried out on samples (0.5\% w/v) with $\phi D M S O$ of 0.3 and 0.4 , solvent fractions that gave the most stable gels in the preliminary vial inversion tests. Initial analyses showed that for both ratios, amplitude (SI.25) and frequency sweeps (Fig. 6B) revealed $G^{\prime}$ values higher than $G^{\prime \prime}$ values of at least one order of magnitude, confirming the LMWG nature of this analogue. Frequency sweeps showed a frequency independence of $\mathrm{G}^{\prime}$ values up to $25.1 \mathrm{rad} / \mathrm{s}$ ( $\phi \mathrm{DMSO}$ of 0.3 ) and 39.8 $\mathrm{rad} / \mathrm{s}$ ( $\phi \mathrm{DMSO}$ of 0.4 ) respectively. $\mathrm{G}^{\prime \prime}$ values displayed slight frequency dependence in the same range considered. With increasing frequencies, breakdown of the gel network was observed. ${ }^{28}$

Figure 6: Frequency sweeps of hydrogel $2(1 \% \mathrm{w} / \mathrm{v})$ performed at $\gamma=1$

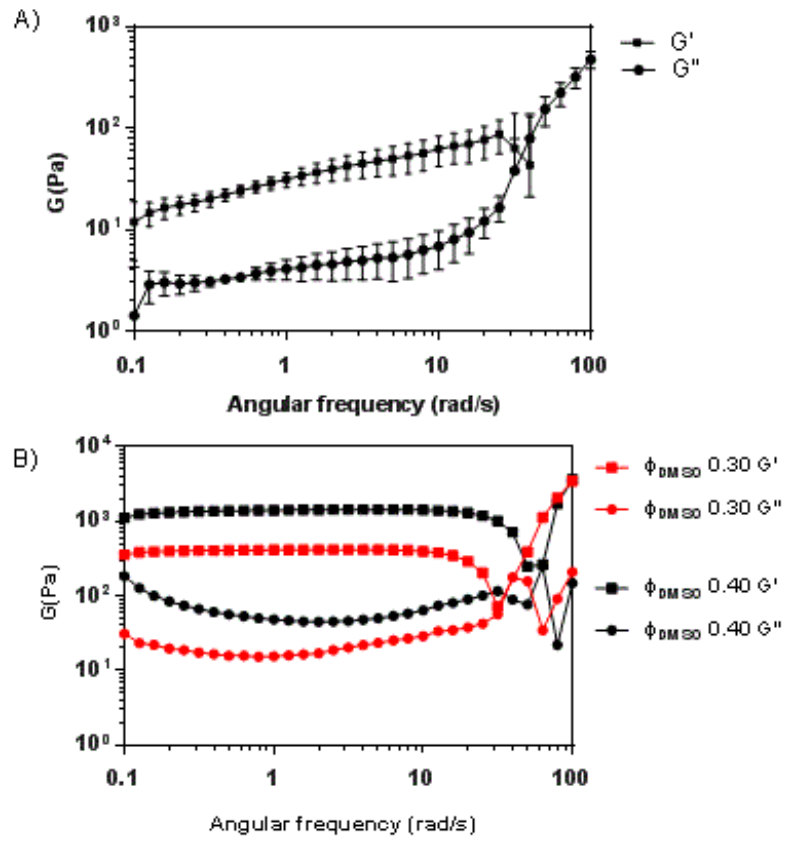

$\%$ and at $37^{\circ} \mathrm{C}(\mathrm{A})$. Frequency sweeps of gel za with $\phi \mathrm{DMSO}$ of 0.3 and $0.4, \mathrm{n}=3$ at $37^{\circ} \mathrm{C}, \gamma=0.5 \%$ and $\omega=0.1-100 \mathrm{rad} / \mathrm{s}$. Standard deviation $<18 \%$ (B). All measurements were carried out in triplicate. Error bars represent standard deviation.

Correlation between $\phi D M S O$ and gel stiffness was also found: a comparison of $G^{\prime}$ values of $3 a$ in the LVR at $\phi$ DMSO of 0.3 and 0.4 showed an increase of this parameter from $\sim 400$ Pa to $\sim 1400$ Pa respectively, thus confirming the effect of DMSO solvent fractions on gel rigidity as previously reported for Fmoc-diphenylalanine hydrogels. ${ }^{29}$ TEM micrographs of derivatives $\mathbf{2}$ and $\mathbf{3 a - 3} \mathbf{c}$ confirmed the presence of fibers in their gel structures (SI.21 and SI.23). However, the two types of derivatives were characterized by completely different fiber populations, in terms of morphology and dimensions. Succinic acid derivative $\mathbf{2}$ formed an entangled network of fibers, with a prevalence of thin fibers with widths in the region of $35-45 \mathrm{~nm}$ and lengths of several microns (Fig. 7A). TEM micrographs of gels of $3 \mathbf{a}$ at $\phi$ DMSO of 0.3 and 0.4 showed the presence of an entangled and dense network of fibers, with no differences between the two ratios tested, in terms of fiber morphology and dimensions. Specifically, both samples displayed a branched pattern of fibers, with formation of thick aggregates with variable widths between $1100 \mathrm{~nm}$ and $400 \mathrm{~nm}$ and lengths from $8 \mu \mathrm{m}$ to $32 \mu \mathrm{m}$ (Fig. $7 \mathrm{~B}$ ).

${ }^{1} \mathrm{H}-\mathrm{NMR}$ spectroscopy analyses of gels of $\mathbf{2}$ and $3 \mathrm{a}-\mathbf{3} \mathbf{c}$ were also carried out to investigate the molecules' functional groups involved in the gelation and the dependence of selfassembly on temperature and pH (SI.17, SI.18, SI.20, SI.22). Time-dependent ${ }^{1} \mathrm{H}$-NMR spectroscopy studies on hydrogel $\mathbf{2}$ revealed the contribution of the alkyl chain in the selfassembly.

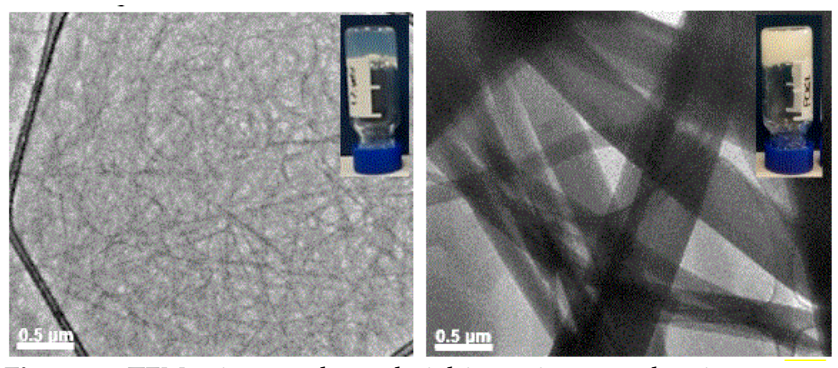

Figure 7: TEM micrographs and vial inversion test showing macroscopic appearance of sample of hydrogel $2(1 \% \mathrm{w} / \mathrm{v}$, scale bar $0.5 \mu \mathrm{m})$, $\mathrm{pH}$ 7.2 (A). TEM micrographs and vial inversion test showing macroscopic appearance of sample of gels of $3 a(0.5 \% \mathrm{w} / \mathrm{v})$ at a) $\$ \mathrm{DMSO}$ of 0.3 (scale bar $0.5 \mu \mathrm{m}, \mathrm{B})$.

Temperature-dependent ${ }^{1} \mathrm{H}-\mathrm{NMR}$ spectroscopy analyses proved the crucial role of the $\pi-\pi$ stacking interactions of the benzothiazole core in gel formation; the hydrogen bonds of the carbamate group also participated in self-assembly.

Lastly, dissolution studies from the gel matrix were performed to prove the potential depot formulations of $\mathbf{2}$ LMWG for localized drug delivery. The hydrogel of $\mathbf{2}$ was selected as the lead candidate to perform these studies as it maintained $\mu \mathrm{M}$ potency but didn't require poorly biocompatible DMSO concentrations to create gels as compared to $3 \mathbf{a}-3 \mathbf{c}$ ( $\phi$ DMSO up to 0.4$)$ making LMWG 2 more suitable for drug delivery purposes. Dissolution studies were carried out under physiological conditions at $37^{\circ} \mathrm{C}$ in

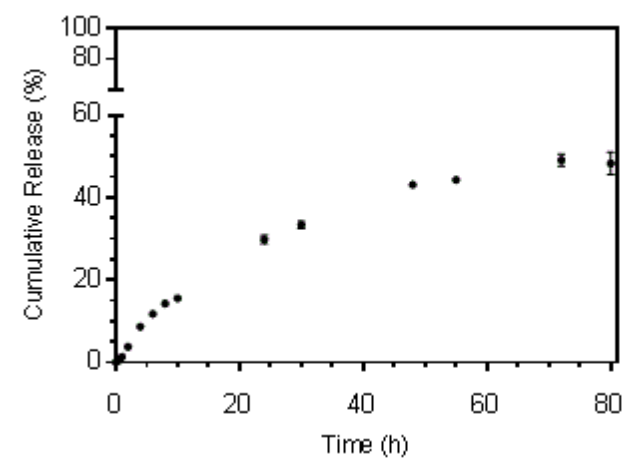

PBS and were performed over 80 h. Results Figure 8: Cumulative release profile of 2 from hydrogel of $2(1 \% \mathrm{w} / \mathrm{v})$ in PBS ( $\mathrm{pH} 7.4$, $37^{\circ} \mathrm{C}$ ). All measurements were carried out in triplicate. Error bars represent standard deviation. 
showed that $48 \%$ of 2 was released from the hydrogel within the time considered (Fig. 8).

\section{DISCUSSION}

Two new series of self-assembling gelators based on the benzothiazole anticancer agent 1 have been successfully developed with the aim of creating a drug delivery platform for this experimental antitumour compound. In the preliminary phase of drug design, two different approaches have been considered. The first series consisted of esterasesensitive carbamate derivatives of $\mathbf{1}$, designed accordingly to the pioneering work of Alexander et al. ${ }^{25}, 26$ This led to the synthesis of the acyloxyalkoxycarbonyl derivatives 3a3d. The succinic acid amide derivative 2, having an alkyl chain and a free carboxylic acid terminus, was then developed with the aim of comparing the rate of conversion into the parent drug and avoiding the rapid esterase-mediated hydrolysis. In terms of gelation, drug design of 2 was developed assuming that the phenyl-benzothiazole moiety of $\mathbf{1}$ would have provided the necessary $\pi-\pi$ stacking interactions for initial self-assembly. Introduction of an alkanoic acid at the $N$-position of the native compound via an amide bond would have created the hydrophobic forces and the hydrogen bond donor and acceptor groups fundamental for the self-assembly. Both amide and carbamate series demonstrated potent antitumour activity in vitro against mammary MCF-7 and ovarian IGROV-1 carcinoma cells. They also displayed selectivity against malignant cell lines, having negligible impact on MRC-5 embryonic lung fibroblast growth. Carbamate deriavtives showed remarkable growth inhibitory activity in the nanomolar range compared to the amide derivative $\mathbf{2}$. This could be attributed to the more rapid hydrolysis of $\mathbf{1}$ from the carbamate derivative compared to the succinic acid derivative. This theory was confimed by the in vitro stability studies in cell growth medium and human plasma: succinic acid derivative $\mathbf{2}$ was stable in both media, whereas the carbamate derivative $3 \mathbf{a}$ displayed complete conversion into the parent amine $\mathbf{1}$. These studies suggested susceptibility of $\mathbf{2}$ to intracellular enzyme and of za to extracellular enzyme-hydrolysis. In fact, acyloxyalkoxycarbonyl derivates, possessing an enzymatically hydrolyzable ester function, readily release the parent drugs from the corresponding derivative as a result of extracellular esterase activity. ${ }^{26}$ Stability studies of 2 in both MCF-7 sensitive- and HCT-116 insensitive cells and their growth medium failed to reveal release of $\mathbf{1}$. A possible explanantion for this in sensitive cells (e.g. MCF-7) could be related to the rapid nature in which aminophenylbenzothiazoles such as $\mathbf{1}$ are sequestered by cytosolic AhR and translocated to the nucleus, $3^{\circ}$ therefore preventing detection of $\mathbf{1}$ by HPLC. An alternative posit could be that $\mathbf{2}$ itself is able to bind cytosolic AhR. Expression of CYP1A1 was weakly induced in MCF-7 cells following their exposure to $\mathbf{2}$, and growth was inhibited, inferring some intracellular conversion of $\mathbf{2}$ to parent amine $\mathbf{1}$, and biotransformation to electrophilic species responsible for DNA damage and subsequent cell growth inhibition / death in sensitive cells which express cytosolic AhR. ${ }^{17}$ More powerful induction of
CYPıA1 was evoked by 1 and $3 a$ - both exhibiting nM potency in MCF-7 and IGROV-1 carcinoma cell lines. Both amide and carbamate series were formulated as LMWGs, yielding hydrogel 2 and organogels $\mathbf{3 a - 3 \mathbf { c }}$ respectively, with the aim of creating platforms for the targeted delivery at the tumour resection site. It was considered that such a formulation, coupled with local delivery would overcome general toxicity associated with the previously developed lysylamide derivative of $\mathbf{1}$ (Phortress), which was administered systemically (I.V.) and formed persistent adducts in DNA rodent lung tissue. ${ }^{31}$ Rheological characterization of hydrogel $\mathbf{2}$ showed formation of a stable LMWG, with a low degree cross-linked network $\left(\mathrm{G}^{\prime} \sim 60 \mathrm{~Pa}\right)$. Carbamate derivatives $3 \mathbf{a}-\mathbf{3 c}$ formed more rigid organogels $\left(\mathrm{G}^{\prime} \sim 10^{3} \mathrm{~Pa}\right)$, with $\phi$ DMSO up to o.4. The gels' mechanical characterization was also confirmed by their morphological inner structure: hydrogel 2 consisted of thin, long fibers within the nanometer range, whereas acyloxyalkoxycarbonyl derivatives $\mathbf{3 a - 3 \mathbf { c }}$ formed thicker aggregates with lengths in the micrometer range. In spite of the higher mechanical strength and greater stability of gels $\mathbf{3 a - 3 c}$, their poorlybiocompatible concentrations of DMSO ( $\phi$ DMSO up to o.4) precluded further development and hydrogel 2 was selected as the lead compound for subsequent dissolution studies. Results showed $48 \%$ release of 2 from the hydrogel matrix over an $80 \mathrm{~h}$ period when incubated in PBS, thus confirming the drug delivery properties of LMWG 2 for localized delivery.

\section{CONCLUSION}

In this work we have reported design and development of novel self-assembling gelators based on 1. Two different types of derivatives were synthesized, formed by an amide (2) and a carbamate (3a-3d) linker, respectively; they maintained selective and potent in vitro antitumour activity against mammary and ovarian carcinoma cells. The ability to form stable gelators under relatively high strains was supported by rheological tests, and their morphology was characterized by a crossed-linked nanostructure. Finally, in vitro dissolution studies proved the ability of hydrogel 2 to act as a delivery platform for localized delivery.

\section{ASSOCIATED CONTENT}

The Supporting Information is available free of charge on the ACS Publications website at DOI:

${ }^{1} \mathrm{H}$ NMR, ${ }^{13} \mathrm{C}$ NMR spectra, RP-HPLC, for compounds 2 and 3a-3d; $\mathbf{1 H}-\mathrm{NMR}$ and TEM analyses, oscillatory amplitude sweeps on gels 2 and 3a-3c; stability test of 2 in HCT-116 cells and their growth medium.

\section{AUTHOR INFORMATON}

Corresponding author: Dr. Maria Marlow.

E-mail: maria.marlow@nottingham.ac.uk

Notes: The authors declare no competing financial interest. This is part 33 in the series "Antitumour Benzothiazoles"; reference 12 is part 32.

\section{ACKNOWLEDGMENT}


This work was supported by the Engineering and Physical Sciences Research Council [grants numbers EP/K503101/1 and EP/M50810X/1]. We are grateful to Mike Fay at the Nottingham Nanotechnology and Nanoscience Centre (NNNC) for his support for the TEM imaging.

1. Skilling, K. J.; Citossi, F.; Bradshaw, T. D.; Ashford, M.; Kellam, B.; Marlow, M. Insights into low molecular mass organic gelators: a focus on drug delivery and tissue engineering applications. Soft Matter 2014, 10, (2), 237-256. 2. Seow, W. Y.; Hauser, C. A. E. Short to ultrashort peptide hydrogels for biomedical uses. Materials Today 2014, 17, (8), 381-388.

3. Tian, R.; Chen, J.; Niu, R. The development of low-molecular weight hydrogels for applications in cancer therapy. Nanoscale 2o14, 6, (7), 3474-3482.

4. Vemula, P. K.; Wiradharma, N.; Ankrum, J. A.; Miranda, O. R.; John, G.; Karp, J. M. Prodrugs as self-assembled hydrogels: a new paradigm for biomaterials. Current Opinion in Biotechnology 2013, 24, (6), 1174-1182.

5. Vemula, P. K.; Cruikshank, G. A.; Karp, J. M.; John, G. Self-assembled prodrugs: An enzymatically triggered drug-delivery platform. Biomaterials 2oo9, 30, (3), 383-393. 6. Majumder, J.; Yedoti, P.; Dastidar, P. A supramolecular topical gel derived from a non-steroidal anti-inflammatory drug, fenoprofen, is capable of treating skin inflammation in mice. Organic $\mathcal{E}$ Biomolecular Chemistry 2015, 13, (8), 2300-2309.

7. $\quad$ Li, Y.; Zhou, F.; Wen, Y.; Liu, K.; Chen, L.; Mao, Y.; Yang, S.; Yi, T. (-)-Menthol based thixotropic hydrogel and its application as a universal antibacterial carrier. Soft Matter 2014, 10, (17), 3077-3085.

8. Gao, Y.; Kuang, Y.; Guo, Z.-F.; Guo, Z.; Krauss, I. J.; $\mathrm{Xu}$, B. Enzyme-Instructed Molecular Self-assembly Confers Nanofibers and a Supramolecular Hydrogel of Taxol Derivative. Journal of the American Chemical Society 2009, 131, (38), 13576-13577.

9. Li, X.; Yang, C.; Zhang, Z.; Wu, Z.; Deng, Y.; Liang, G.; Yang, Z.; Chen, H. Folic acid as a versatile motif to construct molecular hydrogelators through conjugations with hydrophobic therapeutic agents. Journal of Materials Chemistry 2012, 22, (41), 21838-21840.

10. Wang, H.; Lv, L.; Xu, G.; Yang, C.; Sun, J.; Yang, Z. Molecular hydrogelators consist of Taxol and short peptides/amino acids. Journal of Materials Chemistry 2012, 22, (33), 16933-16938.

11. Du, X.; Zhou, J.; Shi, J.; B. Xu. Supramolecular Hydrogelators and Hydrogels: From Soft Matter to Molecular Biomaterials. Chemical Reviews 2015, 115, (24), 13165-13307. 12. Stone, E. L., Citossi, F., Singh,R., Kaur, B., Gaskell, M., Farmer, P.B., Monks, A., Hose,C., Stevens, M.F.G., Leong, C-O., Stocks, M., Kellam, B., Marlow, M., Bradshaw, T.D. Antitumour Benzothiazoles. 32. DNA adducts and double strand breaks correlate with activity; synthesis of ${ }_{5} \mathrm{~F} 203$ hydrogelsfor local delivery. Bioorganic and Medicinal Chemistry 2015, 23, (21), 6891-6899.

13. Hutchinson, I.; Chua, M. S.; Browne, H. L.; Trapani, V.; Bradshaw, T. D.; Westwell, A. D.; Stevens, M. F.

\section{REFERENCES}

G. Antitumor benzothiazoles. 14. Synthesis and in vitro biological properties of fluorinated 2-(4-aminophenyl)benzothiazoles. Journal of Medicinal Chemistry 2001, 44, (9), 1446-1455.

14. Bradshaw, T. Phortress: the smart antitumour agent which induces its own metabolism. The Pharmaceutical Journal 2010, 284, 23.

15. Bazzi, R.; Bradshaw, T. D.; Rowlands, J. C.; Stevens, M. F. G.; Bell, D. 2-(4-Amino-3-methylphenyl)-5fluorobenzothiazole is a ligand and shows species-specific partial agonism of the Aryl Hydrocarbon Receptor. Toxicology and Applied Pharmacology 2009, 1, (237), 102-110.

16. Callero, M. A.; Luzzani, G. A.; De Dios, D. O.; Bradshaw, T. D.; Loaiza Perez, A. I. Biomarkers of Sensitivity to Potent and Selective Antitumor 2-(4-Amino-3Methylphenyl)-5-Fluorobenzothiazole (5F203) in Ovarian Cancer. Journal of Cellular Biochemistry 2013, 114, (10), 2392-2404.

17. Wang, K.; Guengerich, F. P. Bioactivation of Fluorinated 2-Aryl-benzothiazole Antitumor Molecules by Human Cytochrome $\mathrm{P}_{45} \mathrm{OS}_{1} \mathrm{~A}_{1}$ and $2 \mathrm{~W}_{1}$ and Deactivation by Cytochrome $\mathrm{P}_{450} 2 \mathrm{~S}$. Chemical Research in Toxicology 2012, 25, (8), 1740-1751.

18. Tan, B. S.; Tiong, K. H.; Muruhadas, A.; Randhawa, N.; Choo, H. L.; Bradshaw, T. D.; Stevens, M. F. G.; Leong, C-O. CYP2S1 and CYP2W1 Mediate 2-(3,4-Dimethoxyphenyl)-5-Fluorobenzothiazole (GW-610, NSC 721648) Sensitivity in Breast and Colorectal Cancer Cells. Molecular Cancer Therapeutics 2011, 10, (10), 1982-1992.

19. Hutchinson, I.; Jennings, S. A.; Vishnuvajjala, B. R.; Westwell, A. D.; Stevens, M. F. G. Antitumor benzothiazoles. 16. Synthesis and pharmaceutical properties of antitumor 2-(4-aminophenyl)benzothiazole amino acid prodrugs. Journal of Medicinal Chemistry 2002, 45, (3), 744747 .

20. Bradshaw, T. D.; Westwell, A. D. The development of the antitumour benzothiazole prodrug, Phortress, as a clinical candidate. Current Medicinal Chemistry 2004, 11, (8), 1009-1021.

21. Jiao, T.; Ma, K.; Shen, X.; Zhang, Q.; Li, X.; Zhou, J.; Gao, F. Self-Assembly and Soft Material Preparation of Binary Organogels via Aminobenzimidazole/Benzothiazole and Acids with Different Alkyl Substituent Chains. Journal of Nanomaterials 2013, (Article ID 762732,), 11 pages.

22. Shen, X.; Jiao, T.; Zhang, Q.; Guo, H.; Lv, Y.; Zhou, J.; Gao, F. Nanostructures and Self-Assembly of Organogels via Benzimidazole/Benzothiazole Imide Derivatives with Different Alkyl Substituent Chains. Journal of Nanomaterials 2013, (Article ID409087), 8 pages.

23. Rautio, J.; Kumpulainen, H.; Heimbach, T.; Oliyai, R.; Oh, D.; Jarvinen, T.; Savolainen, J. Prodrugs: design and 
clinical applications. Nature Reviews Drug Discovery 2008, 7, (3), 255-270.

24. Simplicio, A. L.; Clancy, J. M.; Gilmer, J. F. Prodrugs for Amines. Molecules 2oo8, 13, (3), 519-547.

25. Alexander, J.; Cargill, R.; Michelson, S. R.; Schwam, H. (Acyloxy)alkyl carbamates as novel bioreversible prodrugs for amines - increased permeation through biological-membranes. Journal of Medicinal Chemistry 1988, 31, (2), 318-322.

26. Gogate, U. S.; Repta, A. J.; Alexander, J. N-(acyloxyalkoxycarbonyl) derivatives as potential prodrugs of amines .1. Kinetics and mechanism of degradation in aqueous-solutions. International Journal of Pharmaceutics 1987 , 40, (3), 235-248.

27. Adams, D. J.; Butler, M. F.; Frith, W. J.; Kirkland, M.; Mullen, L.; Sanderson, P. A new method for maintaining homogeneity during liquid-hydrogel transitions using low molecular weight hydrogelators. Soft Matter 2009, 5, (9), 1856-1862.

28. Peng, J.; Liu, K.; Liu, X.; Xia, H.; Liu, J.; Fang, Y. New dicholesteryl-based gelators: gelling ability and selective gelation of organic solvents from their mixtures with water at room temperature. New Journal of Chemistry 2008, 32, (12), 2218-2224.

29. Raeburn, J.; Pont, G.; Chen, L.; Cesbron, Y.; Levy, R.; Adams, D. J. Fmoc-diphenylalanine hydrogels: understanding the variability in reported mechanical properties. Soft Matter 2012, 8, (4) 1168-1174.

30. Bradshaw, T. D.; Bibby, M. C.; Double, J. A.; Fichtner, I.; Cooper, P. A.; Alley, M. C.; Donohue, S.; Stinson, S. F.; Tomaszewjski, J. E.; Sausville, E. A.; Stevens, M. F. G. Preclinical evaluation of amino acid Prodrugs of novel antitumor 2-(4-amino-3-methylphenyl)benzothiazoles. Molecular Cancer Therapeutics 2002, 1, (4), 239-246.

31. Bradshaw, T. D.; Wren, J. E.; Bruce, M.; Barrett, D. A.; Leong, C. O.; Gaskell, M.; Wright, E. K.; Farmer, P. B.; Henderson, C. J.; Wolf, R.; Stevens, M. F. G. Preclinical Toxicokinetic Evaluation of Phortress 2-(4-Amino-3Methylphenyl)-5-Fluorobenzothiazole Lysylamide Dihydrochloride in Two Rodent Species. Pharmacology 2009, 83, (2), 99-109. 